\title{
PERBANDINGAN PERFORMANSI MESIN REFRIGERASI KOMPRESI UAP CHEST FREEZER MENGGUNAKAN PIPA KAPILER DAN ORIFICE
}

\author{
Ferry Sugara ${ }^{1}$, Bobi Khoerun ${ }^{2}$ \\ 1,2Politeknik Negeri Indramayu, Jl. Lohbener Lama no.8 Kabupaten Indramayu \\ ${ }^{1}$ ferrysugara78@gmail.com, ${ }^{2}$ hubbikhoiron31@gmail.com
}

\begin{abstract}
Abstrak
Chest freezer adalah refrigerator penyimpanan dan membekukan makanan secara cepat, sangat efektif untuk menyimpan bahan makanan beku supaya kualitas makanan tetap baik. Adapun suhu pendinginan chest frezer dapat mencapai $-28^{\circ} \mathrm{C}$. Suhu serendah itu memang dibutuhkan karena fungsi utama freezer ini adalah untuk membekukan bahan makanan sehingga dapat bertahan lebih lama. Tujuan dari penelitian ini adalah Mengetahui performansi mesin chest freezer dengan membandingkan alat ekspansi berupa pipa kapiler dengan orifice dengan diameter yang berbeda, sehingga mengetahui perbedaan penggunaan performansi mesin yang lebih efisien. Metode yang dipakai dalam penelitian kali ini adalah melakukan pengujian,performansinya dengan mengukur temperatur dan tekanan di setiap komponen utamanya saat sistem dalam keadaan steady. Hasil penelitian COP aktual rata-rata diameter pipa kapiler 0,028 inchi adalah 2,16, sedangkan nilai COP aktual rata-rata orifice 0,031 inchi adalah 2,74. Adapun nilai efisiensi refrigrasi pipa kapiler diameter 0,028 inchi sebesar $63,58 \%$, sedangkan untuk orifice diameter 0,031 inchi memiliki nilai efesiensi refrigrasi $59,49 \%$ dan temperatur kabin di pipa kapiler diameter 0,028 inchi nilai rata-rata dengan temperatur sebesar $-9,82^{\circ} \mathrm{C}$. Sedangkan untuk orifice diameter 0,031 inchi lebih kecil memiliki nilai rata-rata lebih dingin yakni sebesar $-9,09^{\circ} \mathrm{C}$.
\end{abstract}

Kata Kunci: pipa kapiler, orifice dan COP.

\begin{abstract}
Chest freezer is a refrigerator storage and freeze food quickly, very effective for storing frozen food ingredients so that food quality remains good. The chest freezer cooling temperature can reach $-28^{\circ} \mathrm{C}$. Such a low temperature is needed because the main function of this freezer is to freeze food ingredients so that they can last longer. The purpose of this study was to determine the performance of the chest freezer machine by comparing the expansion device in the form of a capillary tube with orifice with different diameters, so as to know the difference in the use of a more efficient machine performance. The method used in this research is to test its performance by measuring temperature and pressure in each of its main components when the system is steady. The results of the actual COP research mean that the average 0.028 inch capillary pipe diameter was 2.16, while the actual COP value of 0.031 inch orifice was 2.74. The value of the refrigeration efficiency value of 0.028 inch capillary pipe is $63.58 \%$, while for orifice diameter 0.031 inch has a refrigeration efficiency value of 59.49\% and the cabin temperature in the capillary pipe diameter is 0.028 inch, the average value is $-9.82{ }^{\circ} \mathrm{C}$. Where as for the smaller orifice with a diameter of 0.031 inches, it has a cooler average value of $-9.09^{\circ} \mathrm{C}$
\end{abstract}

Keywords: kapiler tube, orifice, COP. 


\section{PENDAHULUAN}

Teknologi pembekuan makanan saat ini telah berkembang pesat sedemikian rupa sehingga peranannya begitu terasa sekali dan telah menyentuh berbagai aspek kehidupan manusia, terutama yang berkaitan dengan proses pengolahan dan pembekuan makanan ataupun minuman. Proses pendinginan refrigerasi pada hakekatnya merupakan proses Pemindahan energi panas yang terkandung didalam ruangan tersebut. Sesuai dengan hukum kekekalan energi maka kita tidak dapat menghilangkan energi Tetapi hanya dapat memindahkannya dari suatu subtansi kesubtansi lainnya. Untuk keperluan pemindahan energi panas ruangan, dibutuhkan suatu fluida Penukar kalor yang disebut refrigeran. (Widodo, 2018). Sedangkan menurut Hartanto (1985) pendinginan refrigerasi adalah suatu proses penyerapan Panas pada suatu benda dimana proses ini terjadi karena proses penguapanbahan pendingin (refrigeran).

Chest freezer merupakan salah satu tempat penyimpanan makanan yang umum dijumpai ditengah-tengah masyarakat.metode pengembangan teknologi pada penyimpanan makanan dan minuman pun bervariasi guna untuk meningkatkan efisiensi baik dari kinerja mesinnya dan energi yang digunakan. Banyak studi yang di ilakukan untuk mendapatkan pengaruh geometri pipa kapiler terhadap performansi sistem. Pathak (2014) dari review literatur yang dilakukan bahwa geometrik pipa kapiler seperti panjang dan diamater berpengaruh terhadap penurunan tekanan, $\mathrm{COP}$, dan laju aliran massa refrigeran.

\section{METODE}

Tahap tahap penelitian berdasarkan flowchart pada gambar 1 dibawah ini:

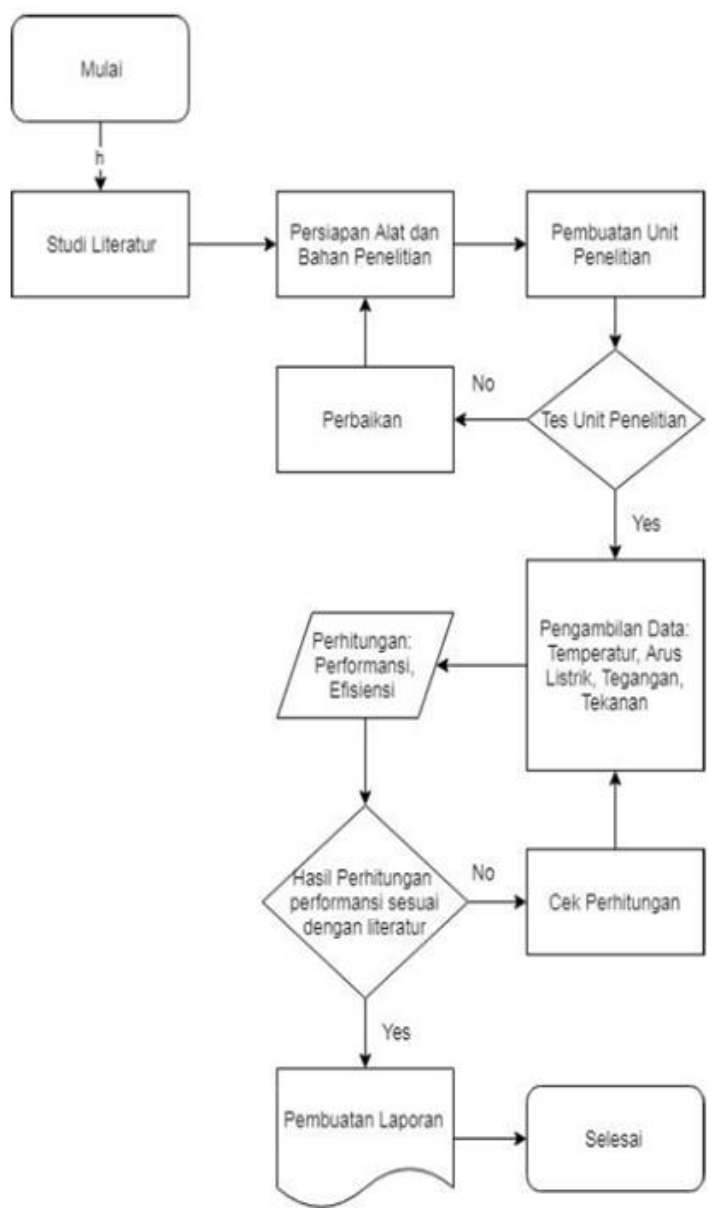

Gambar 1. Flowchart penelitian

\subsection{Dimensi pipa kapiler}

Konfigurasi dan dimensi pipa kapiler dengan berbagai macam variasi seperti yang diperlihatkan table berikut:

Tabel 1. Data ukuran pipa kapiler (using straight capillary tube) in this investigation fall within the results of Jung et al. (1999), Kim et al. (2002) and Akintunde (2004a)

\begin{tabular}{|c|c|c|c|c|c|c|c|c|c|c|c|c|c|c|}
\hline \multicolumn{15}{|c|}{ Helical-coiled capillary tubes } \\
\hline \multicolumn{3}{|c|}{$d_{1}=80$} & \multicolumn{3}{|c|}{$d_{2}=100$} & \multicolumn{3}{|c|}{$d_{3}=120$} & \multicolumn{3}{|c|}{$d_{4}=160$} & \multicolumn{3}{|c|}{$d_{5}=200$} \\
\hline$p_{1}$ & $p_{2}$ & $P_{3}$ & $p_{1}$ & $p_{2}$ & $p_{3}$ & $p_{1}$ & $p_{2}$ & $p_{3}$ & $p_{1}$ & $p_{2}$ & $p_{3}$ & $p_{1}$ & $p_{2}$ & $p_{3}$ \\
\hline 4 & 6 & 10 & 6 & 8 & 10 & 6 & 8 & 10 & 6 & 8 & 10 & 6 & 8 & 10 \\
\hline \multicolumn{15}{|c|}{ Serpentine-coiled capillary tubes } \\
\hline \multicolumn{3}{|c|}{$h_{1}=80$} & \multicolumn{3}{|c|}{$h_{2}=100$} & \multicolumn{3}{|c|}{$h_{3}=120$} & \multicolumn{3}{|c|}{$h_{4}=160$} & \multicolumn{3}{|c|}{$h_{5}=200$} \\
\hline
\end{tabular}


Tabel 2. Ukuran dimensi orifice plate. Roger Legg, in Air Conditioning System Design, 2017

$$
\begin{array}{ll}
\beta & \sigma \\
0.20 & 0.598 \\
0.22 & 0.598 \\
0.24 & 0.599 \\
0.26 & 0.600 \\
0.28 & 0.601 \\
0.30 & 0.602 \\
0.32 & 0.603 \\
0.34 & 0.605 \\
0.36 & 0.606 \\
0.38 & 0.608
\end{array}
$$

$\eta_{R}$

COPaktual

COP carnot carnot
$=$ Effisiensi refrigerasi

$=$ Coefficient of Performance aktual

= Coefficient of Performance

\subsection{Koefisien Kinerja Sistem atau Coeffisient of Performance (COP)}

Selain kerja kompresor dan kapasitas penyerapan panas di evaporator, pada sistem refrigrasi kompresi uap juga dikenal istilah coefficient of performance (COP) yang mana nilai COP tersebut merupakan suatu nilai perbandingan antara kapasitas penyerapan panas yang terjadi di evaporator. Dengan sejumlah kerja kompresi yang dilakukan di kompresor atau dengan kata lain (Hermawan W, 2008):

COP ini digunakan untuk mengetahui kualitas kerja dari suatu mesin refrigerasi.

Efek refrigerasi $q_{e}=h_{1}-h_{4}(\mathrm{~kJ} / \mathrm{kg})$

Kerja spesifik $w=h_{2}-h_{1}(\mathrm{~kJ} / \mathrm{kg})$

Efek kondensasi $\quad q_{c}=h_{2}-h_{3}(\mathrm{~kJ} / \mathrm{kg})$

Prestasi aktual mesin refrigerasi dapat diketahui dengan menggunakan persamaan sebagai berikut :

$\operatorname{COP}_{\text {aktual }}=\frac{q_{e}}{w}=\frac{h_{1}-h_{4}}{h_{2}-h_{3}}$

dengan,

$\mathrm{COP}_{\text {aktual }}=$ Coefficient of Performance aktual

$q_{e} \quad=$ Efek refrigerasi $(\mathrm{kJ} / \mathrm{kg})$

$\mathrm{w}=$ Kerja kompresi $(\mathrm{kJ} / \mathrm{kg})$

dan kualitas idealnya dapat dihitung dengan menggunakan persamaan $\mathrm{COP}_{\text {carnot}}$, sebagai berikut:

$$
C O P_{\text {carnot }}=\frac{T_{e}}{T_{k}-T_{e}}
$$

Dengan:

$$
\begin{aligned}
& \text { COP carnot }=\text { Coefficient of Performance } \\
& \text { carnot } \\
& T_{k} \quad=\text { Temperatur evaporasi (K) } \\
& T_{e} \quad=\text { Temperatur kondensasi }(\mathrm{K})
\end{aligned}
$$

Sedangkan untuk menghitung efisiensi mesin refrigerasi dapat diperoleh dengan membandingkan nilai $C O P_{\text {aktual }}$ dengan $C O P_{\text {carnot }}$,

$\boldsymbol{\eta}_{\boldsymbol{R}}=\frac{\boldsymbol{C O P}_{\text {aktual }}}{\boldsymbol{C O P}_{\text {carnot }}} \times 100 \%$ dengan ;

\subsection{Komponen modifikasi}

Komponen modifikasi dalam penelitian ini diantaranya adalah:

1. Dua unit pipa kapiler, pipa kapiler 1. diameter 0,028 inci dengan panjang 1,3 meter. Orifice. Diameter 0,034 inci.

2. Pipa tembaga, untuk instalasi rangkaian sistem refrigerasi modifikasi.

3. Soldering Fitting, Digunakan untuk perakitan instalasi yang terbuat dari :
a) Socket (coupling),
b) Reducing solder coupling,
c) $T$ - socket (socket cabang T), dan Flare fitting dan flare nuts.

4. Stop valve, berfungsi sebagai kran pengatur sirkulasi

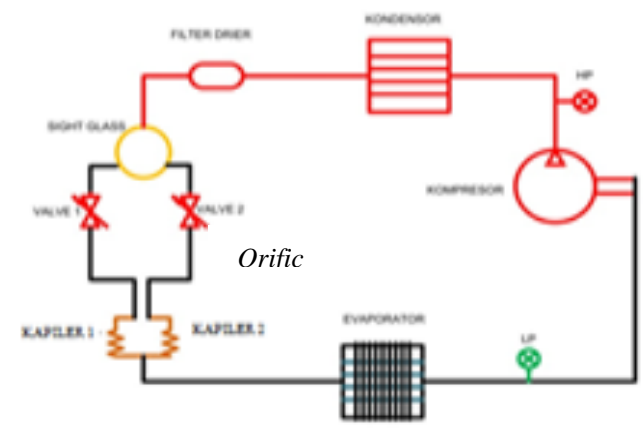

Gambar 2. Skema instalasi pengujian

Dengan bagian-bagian sebagai berikut:

1. Kompresor

2. Kondensor

3. Sight glass

4. Hand valve

5. Pipa kapiler

6. Evaporator

\section{Diagram PH}

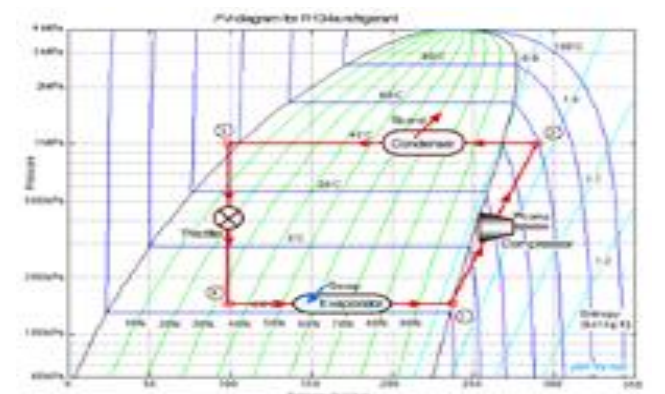

Gambar 3. Diagram P-h sistem refrigerasi dengan kapiler 
Pada Gambar 3 menunjukan proses refrigerasi antara titik, $1-2$ kompresi, Proses ini berlangsung di kompresor secara isentropic adiabatic. Titik 2-3 proses penurunan temperatur pada kondensor.Titik 3-4 Proses ekspansi Proses ini berlangsung secara isoentalpi, hal ini berarti tidak terjadi penambahan entalpi tetapi drop tekanan dan penurunan temperatur. Titik 4-1 Proses Evaporasi. Proses ini berlangsung di evaporator secara isobar isothermal.

\section{HASIL DAN PEMBAHASAN}

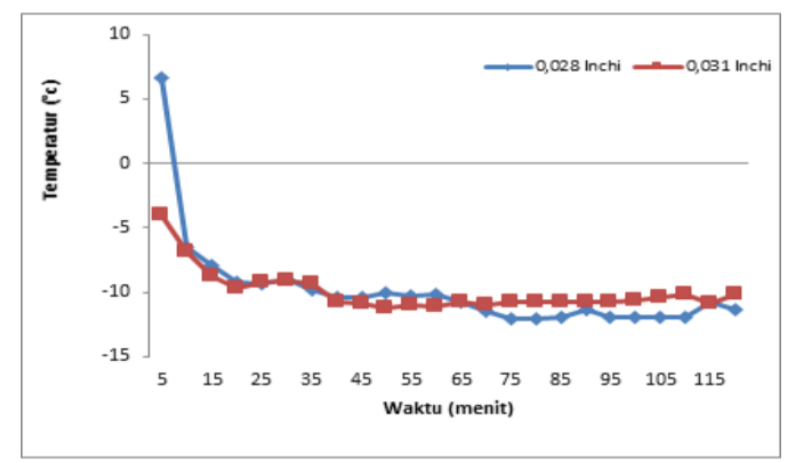

Gambar 4. Temperatur kabin terhadap waktu pada diameter pipa Kapiler $\mathbf{0 , 0 2 8}$ Inchi orifice $\mathbf{0 , 0 3 1}$

Pada Gambar 4 menunjukan temperatur udara kabin pada orifice 0,031 inchi rata - rata dengan temperature sebesar $-9,82^{\circ} \mathrm{C}$. sedangkan untuk pipa kapiler diameter 0,028 inchi memiliki nilai rata rata lebih dingin sebesar $-9,09$. Penggunaan diameter pipa kapiler yang baik adalah dengan menggunakan diameter pipa kapiler 0,028 inchi.

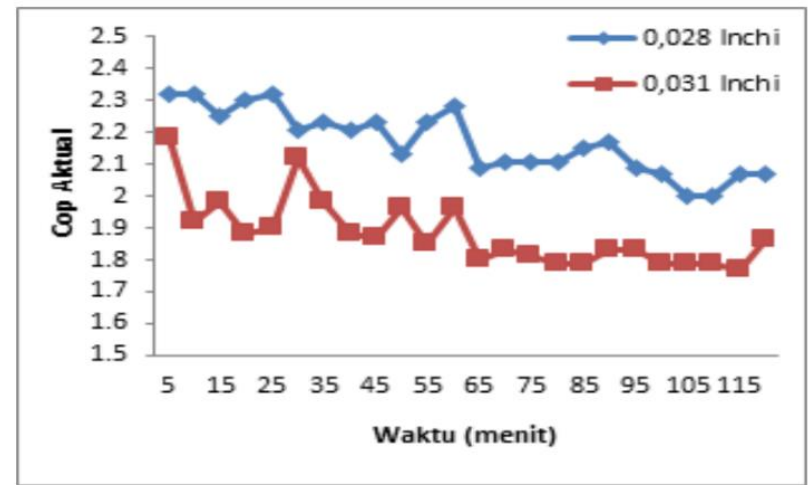

Gambar 5. perbandingan $\mathrm{COP}_{\text {actual }}$ terhadap waktu pada pipa kapiler 0,028 inchi dan 0,031 inchi

Gambar 5 menunjukan bahwa perbedaan yang jelas bahwa koefisien prestasi pada masing-masing perlakuan diameter pipa kapiler 0,028 inchi dan orifice 0,031 inchi cenderung stabil. Disamping itu dapat diketahui bahwa penggunaan diameter pipa kapiler 0,028 inchi COP Aktual lebih tinggi dibandingkan dengan orifice 0,031 inchi, dengan nilai COP aktual maksimal dapat mencapai 2,16.

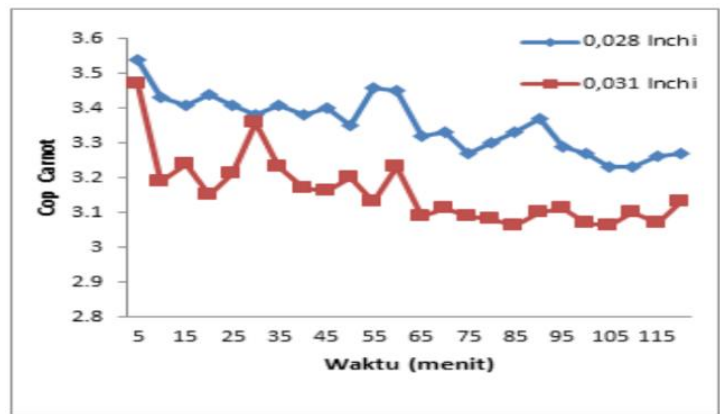

Gambar 6. COP carnot terhadap waktu pada diameter kapiler 0,028 inchi dan 0,031 inchi

Gambar 6 menunjukan bahwa diameter pipa kapiler 0,028 inchi rata-rata COP Carnot 3,35 dan orifice diameter 0,031 inchi rata-rata 3,15. Menyimpulkan semakin besar diameter pipa kapiler maka COP semakin menurun.

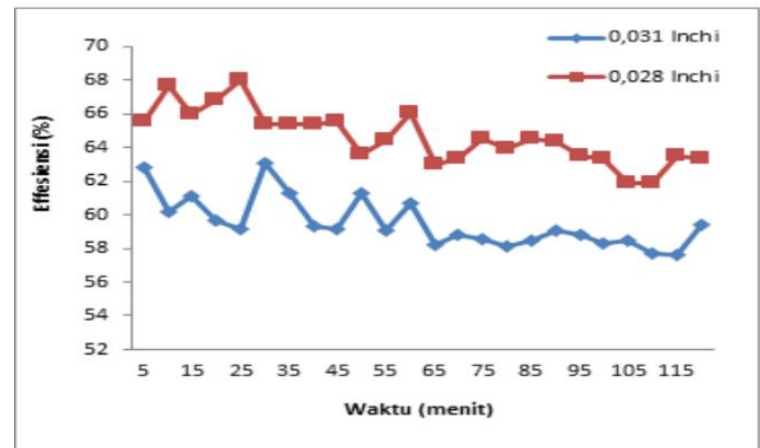

Gambar 7. Perbandingan Effesiensi terhadap waktu,pada Diameter

Pipa Kapiler 0,028 inchi dan orifice 0,031 inchi menunjukan bahwa penggunaan pipa kapiler dengan diameter 0,028 inchi diketahui nilai rata-rata effesiensi $63,58 \%$. Diketahui nilai rata-rata penggunaan orifice 0,031 inchi memiliki nilai effesiensi sebesar 59,49\%.

Tabel 3. Kinerja pipa kapiler dan Orifice terhadap mesin pendingin

\begin{tabular}{|c|c|c|c|c|c|c|c|c|}
\hline No & $\begin{array}{c}\text { Alat } \\
\text { Ekspansi }\end{array}$ & $\begin{array}{l}\mathrm{qw} \\
(\mathrm{kJ} / \mathrm{k} \\
\mathrm{g})\end{array}$ & $\begin{array}{c}\mathrm{qe}_{\mathrm{e}} \\
(\mathrm{k} / \mathrm{kg})\end{array}$ & $\underset{(\mathrm{k} / \mathrm{kg})}{\mathrm{qc}}$ & $\begin{array}{l}\text { COP } \\
\text { alktual }\end{array}$ & $\begin{array}{l}\text { COP } \\
\text { canot }\end{array}$ & $\pi(96)$ & $\begin{array}{l}m \\
(\mathrm{kgg} / \mathrm{s}\end{array}$ \\
\hline 1 & $\begin{array}{l}\text { Kapiler } \\
0,028 \text { inchi }\end{array}$ & 52 & 111 & 163 & 2,13 & 3,35 & 63,58 & $\begin{array}{c}0,003 \\
38\end{array}$ \\
\hline 2 & $\begin{array}{l}\text { Orifice } \\
0,031 \text { inchi }\end{array}$ & 53 & 100 & 153 & 1,88 & 3,16 & 59,49 & $\begin{array}{c}0,003 \\
32\end{array}$ \\
\hline
\end{tabular}




\section{PENUTUP}

\section{Kesimpulan}

Kesimpulan yang diperoleh dari penelitian ini diantaranya adalah:

a. Nilai COP aktual yang diperoleh secara rata-rata adalah dengan nilai yang terbesar dari alat ekspansi pipa kapiler diameter 0,028 inchi yaitu 2,16 dan kemudian yang paling kecil adalah COP orifice 0,031 inchi dengan nilai rata-rata COP aktual sebesar 1,88 .

b. Rata-rata nilai COP carnot pipa kapiler diameter 0,028 inchi memiliki nilai lebih besar yaitu 3,35 sedangkan untuk orifice 0,031 inchi nilai rata-rata COP carnot paling kecil yaitu 3,15 meskipun jarak perbedaannya tidak terlalu jauh.

c. Untuk nilai efisiensi refrigrasi terbesar pada nilai rata-rata adalah pipa kapiler diameter 0,028 inchi sebesar $63,58 \%$. Sedangkan orifice 0,031 inchi lebih kecil memiliki nilai efesiensi refrigrasi rata-rata 59,49\%.

d. Temperatur kabin pada pipa kapiler diameter 0,028 inchi nilai rata-rata dengan temperatur sebesar $-9,82{ }^{\circ} \mathrm{C}$. Sedangkan untuk orifice 0,031 inchi lebih kecil memiliki nilai rata-rata lebih dingin yakni sebesar $-9,09{ }^{\circ} \mathrm{C}$.

\section{DAFTAR PUSTAKA}

Pathak S.S., Shukla P., Chauhan S., Effect of Capillary Tube on The Performanceof a Simple Vapour Compression Refrigeration System, IOSR Journal of Mechanical and Civil Engineering, Vol 11,2014, pp: 5-7.

Roger Legg. 2017. Air Conditioning System Design. Butterworth-Heinemann, Amerika Serikat.

Stoecker, W.F dan J.W. Jones. 1982. Refrigrasi dan Pengkondisian Udara Edisi Kedua. Jakarta: Erlangga.

Wayan Adi Subagia dan I Dewa Made Susila. 2016. Pengaruh Variasi Diameter Pipa Kapiler Pada Siklus Temperatur Rendah Terhadap Performansi Trainer Unit Sistem Refrigerasi Cascade. Bali: Teknik Pendingin dan Tata Udara. Politeknik Negeri Bali Bukit Jimbaran.
Wei, C.Z., 2001. An experimental study of the performance of tubes for R-407c refrigerant. ASHRAE Trans, 27:634-8.

Widodo, Sapto dan Syamsuri Hasan. 2008. Sistem Refrigrasi dan Tata Udara Jilid 1. Jakarta. 